\section{ALLOGRAFT HEART VALVE STERILIZATION: A SIX-YEAR IN-DEPTH ANALYSIS OF A TWENTY-FIVE-YEAR EXPERIENCE WITH LOW- DOSE ANTIBIOTICS}

At the Prince Charles Hospital, from a 25-year experience with allograft heart valves (1969 to 1994), a 6-year analysis from March 1988 to August 1994 of the contamination rates and efficiency of a short-duration, low-dose antibiotic sterilization protocol was made. This analysis covered 642 collections and 680 aortic and pulmonary valve implants. Tissue samples obtained at collection, valve trimming, postantibiotic incubation, and implant provided the raw data. At collection, valves retrieved in open mortuaries produced the highest contamination rate of $54 \%$. Minimal exposure to antibiotics during transport and trimming reduced the contamination rate to $11 \%(p<0.05)$. This was similar to the contamination rate at trimming for valves collected in the "sterile" operating room from multiorgan donors (12\%). Antibiotic incubation at $37^{\circ} \mathrm{C}$ for 6 hours reduced the contamination rate to $4 \%(p<0.05)$. Only valves that showed no contamination at cryopreservation were implanted. However, at implant, resected tissue from valves that had been incubated in antibiotics showed a contamination rate of $3 \%$, presumably from the theater environment, compared with $15 \%(p<0.05)$ for tissue from valves that had not been incubated. A residual antibiotic effect appears present at the time of implant in valves that have been incubated in antibiotics and may assist in the reduction of and resistance to infection in the immediate postoperative period. This is supported by the low incidence of endocarditis in the first 3 postoperative months. The simple and effective protocol of collection within 24 hours of death combined with low-dose antibiotic sterilization is sufficient to produce pathogenfree valves in the majority of cases (>95\%). (J THORAC CARDIovasC SURG 1995;110:680-7)

Ken Gall, BAS, Susan Smith, BSc, Christene Willmette, EN, Mae Wong, FRCPA, and Mark O'Brien, FRACS, FRCS, Brisbane, Australia
$T^{\mathrm{h}}$ he clinical use of allograft valves for aortic valve replacement has been markedly limited by their availability. Whereas in many centers allograft valves have been obtained primarily from multiorgan donors, supply has been increased by postmortem retrieval and retrieval from the excised heart of the transplant recipient. Even so, all three sources may be insufficient to meet clinical requirements.

In the past postmortem retrieval necessitated the

From the Department of Cardiac Surgery, The Prince Charles Hospital, Chermside, Brisbane, Australia.

Received for publication August 11, 1994.

Accepted for publication Jan. 11, 1995.

Address for reprints: Mark F. O'Brien, FRACS, FRCS, Department of Cardiac Surgery, The Prince Charles Hospital, Rode Rd., Chermside, Brisbane 4032, Australia.

Copyright (C) 1995 by Mosby-Year Book, Inc.

$0022-5223 / 95 \$ 5.00+0 \quad \mathbf{1 2} / \mathbf{1} / \mathbf{6 3 2 0 1}$ use of chemical, irradiation, or other harsh methods of valve sterilization that, coupled with the methods of storage, ${ }^{1,2}$ led to poor clinical durability. ${ }^{3,4}$ As a result, interest in the use of the allograft waned during the 1965 to 1980 era. The inherent problem of microbial contamination from the mortuary atmosphere and the respiratory and gastrointestinal systems after death had to be overcome without damaging the valve. ${ }^{5}$ Gentle antibiotic sterilization produced a valve that could be stored at $4^{\circ} \mathrm{C}^{6}$ and, since the mid-1970s, cryopreserved in liquid nitrogen. ${ }^{7}$

Allograft valves were first used at The Prince Charles Hospital (TPCH) in 1969 and the clinical results of allografts stored at $4^{\circ} \mathrm{C}$ and after early cryopreservation have been documented. ${ }^{8-11}$ Interest in the maintenance of valve leaflet viability, ${ }^{12}$ considered a probable important determinant of long-term function, ${ }^{13-14}$ led to a review of the anti- 
Table I. Evolution of TPCH allograft valve antibiotic sterilization and storage protocol

\begin{tabular}{ccccc}
\hline Era & Antibiotics & $37^{\circ}$ C incubation & & Storage time \\
time $($ hr $)$ & Storage type & maximum \\
\hline $1969-75$ & P, S, A & 24 & Refrigerated $4^{\circ} \mathrm{C}$ & 72 days \\
$1975-88$ & P, S, A & 24 & Cryopreserved & Indefinite \\
$1988-$ & P, S & 6 & Cryopreserved & Indefinite \\
\hline
\end{tabular}

$P$, Penicillin (30 $\mu \mathrm{g} / \mathrm{ml}) ; S$, streptomycin $(50 \mu \mathrm{g} / \mathrm{ml}) ; A$, amphotericin B $(10 \mu \mathrm{g} / \mathrm{ml})$.

biotic sterilization protocol at TPCH in March 1988. Formerly, from 1969 to 1988, low-dose penicillin, streptomycin, and amphotericin $\mathrm{B}$ were the antibiotics used to sterilize valve tissue by incubation in nutrient medium for 24 hours at $37^{\circ} \mathrm{C}$. The antifungal agent, amphotericin $\mathrm{B}$, was removed from the antibiotic mixture because of its deleterious effects on cell viability during the cryopreservation process, which left a low-dose antibiotic mixture of penicillin and streptomycin. Incubation time was reduced when a series of bacteriologic tests at TPCH indicated that a 6 -hour incubation in antibiotics was just as effective as a 24-hour incubation in reducing microbial contamination. The tissue from beatingheart donors received a minimal antibiotic exposure of 30 to 60 minutes at room temperature during processing of the valve, whereas tissue obtained from postmortem donors received a 6 -hour $37^{\circ} \mathrm{C}$ incubation before cryopreservation. Because antibiotics act against organisms during their replication, it is maintained that maximum antibiotic action is achieved by incubation of tissue at $37^{\circ} \mathrm{C}$. In addition, cellular viability may be improved at $37^{\circ} \mathrm{C}$ rather than at $4^{\circ} \mathrm{C}$. Antibiotic sterilization at $4^{\circ} \mathrm{C}$ has never been used at TPCH. Even during the period 1969 to 1975 , before cryopreservation, valves were always incubated in antibiotics at $37^{\circ} \mathrm{C}$ before $4^{\circ} \mathrm{C}$ storage in nutrient medium without antibiotics. In April 1991, results of a review of contamination rates in multiorgan donor valves retrieved in an operating room led to these valves also being incubated for 6 hours at $37^{\circ} \mathrm{C}$.

Thus the current sterilization protocol is lowdose and short exposure to minimize any harmful effects on valve viability. This objective was achieved with strict sterility testing during all phases of processing with the eventual production of a pathogen-free valve for implantation. The evolution of the antibiotic sterilization and storage protocols for allograft valves at TPCH since 1969 is expressed in Table I.

Various alternative antibiotic sterilization protocols have been developed by others with different
Table II. Collection types and postcollection treatment

\begin{tabular}{lc}
\hline \multicolumn{1}{c}{ Type and treatment } & No. \\
\hline Donor & \\
With $37^{\circ} \mathrm{C}$ incubation in antibiotics $(6 \mathrm{hr})$ & 53 \\
$\quad$ Multiorgan donor & \\
No incubation & 71 \\
$\quad$ Multiorgan donor & 47 \\
Heart transplant recipient & 171 \\
Total donor & \\
Postmortem & 345 \\
Collection solution with antibiotics & 126 \\
No collection solution & 471 \\
Total postmortem & 642 \\
Total collections & \\
\hline
\end{tabular}

antibiotics, concentrations, exposure times, and incubation temperatures. ${ }^{15-17}$ This paper examines the allograft valve contamination rates and the efficiency of sterilization by the short, low-dose protocol currently in use at TPCH. The analysis covers the experiences of a surgical unit that now implants some 150 allograft valves each year in cases of acquired and congenital heart disease.

\section{Material and methods}

Valve collection type. During the period of review, from March 1988 to August 1994, 642 collections were made from two distinct sources termed donor and postmortem. Beating-heart multiorgan donors and hearts from heart transplant recipients, both retrieved in operating rooms, provided 171 donor valve collections. Procurement immediately before postmortem examination provided 471 postmortem collections. Among these retrievals, 345 were from the large open mortuary room and 126 were done in a "clean room" environment apart from the main mortuary room. For postmortem retrievals the skin was carefully sterilized and the body draped as for a surgical operation and the excision was regarded as a "clean" nonsterile procedure. Procurement of heart valves from postmortem sources has always been rigidly maintained within 24 hours of death (mean death to collection time: 15 hours). The antibiotic procedure and the effectiveness of sterilization of valves from the two sources, donor and postmortem, were collated into subgroups according to the step-by-step procedures after collection. The 
numbers and subgroups of the collection types are shown in Table II.

Microbiology specimens. Fungal and bacterial contamination of the allograft valves was monitored by strict sterility testing of specimens during the collection and processing steps. Specimens were obtained as follows.

Collection. The amount of tissue obtained and the shipping method were dependent on the collection type and source. For donor collection, the entire heart was shipped, double wrapped, in sterile plastic bags on wet ice. Samples for sterility testing were not obtained at retrieval from such donor collections. The majority of postmortem valves were obtained as a heart-valve block consisting of the aortic and pulmonary valves, anterior leaflet of the mitral valve, subvalvular myocardium, and associated great vessels. The heart-valve blocks were placed in the collection solution, which consisted of nutrient medium 199 (M199; CSL, Parkville, Victoria, Australia) containing the antibiotics (M199+AB) penicillin (CSL) $(30 \mu \mathrm{g} / \mathrm{ml})$ and streptomycin (CSL) $(50 \mu \mathrm{g} / \mathrm{ml})$. Valves were transported on cold packs to TPCH allograft heart valve unit. Postmortem collections into M199+AB provided a tissue sample at collection, a pericardial swab, and the collection solution for sterility testing. Postmortem valve collections from clean rooms resulted in heart-valve blocks and entire hearts being shipped without $\mathrm{M} 199+\mathrm{AB}$ in doublewrapped sterile plastic bags on wet ice. Postmortem retrievals without M199+AB provided a pericardial swab only for sterility testing at the time of collection.

Trimming. All valves were processed within 6 hours of receipt. The vast majority were trimmed immediately. Early in the TPCH experience, trimming of the valves was done in an operating theater. In more recent years, a lamina flow cabinet in a clean room dedicated to heart valve processing has been used. All valves were regularly moistened with $\mathrm{M} 199+\mathrm{AB}$ to ensure leaflets did not dehydrate during the trimming process. After trimming, all valves were rinsed in M199 without antibiotics to wash off any blood and adhering tissue pieces. The rinse solution did not contain antibiotics and was used to promote the growth of any contaminating organisms that may have been on the surface of the tissue. Samples of tissue trimmings and the rinse solution were used for sterility testing.

Incubation. All postmortem valves were incubated in $\mathrm{M} 199+\mathrm{AB}$ for 6 hours at $37^{\circ} \mathrm{C}$ before cryopreservation. Donor valves from multiorgan donors since April 1991 were similarly incubated, whereas those from heart transplant recipients were not incubated. A piece of tissue was included with each incubated valve for sterility testing after valve incubation.

Cryopreservation. Valves were cryopreserved in $100 \mathrm{ml}$ M199 (without antibiotics) with $10 \%$ dimethyl sulfoxide (DMSO) (Merck, Darmstadt, Germany) at a rate of approximately $-1^{\circ} \mathrm{C}$ per minute in a controlled rate freezer (model 1010A, Cryomed, Mt. Clemens, Mich.) to a temperature of $-40^{\circ} \mathrm{C}$ and then transferred to the vapor phase of a liquid nitrogen freezer $(17 \mathrm{~K}$, TaylorWharton, Indianapolis, Ind.) at temperatures lower than $-135^{\circ} \mathrm{C}$. A piece of incubated tissue, the incubation solution, and a sample of the freezing solution were used for sterility testing.
Thawing and clinical implantation. For implantation the valves were thawed in a $37^{\circ} \mathrm{C}$ saline bath followed by a 4 by 2 -minute sequential dilution washout of the cryoprotectant (5\% DMSO, 2.5\% DMSO, M199 only, M199 only). Tissue segments from the trimming of the valve before insertion at the surgical operating table and the freezing solution were used for sterility testing. Only those valves implanted at TPCH are included in this analysis.

Microbiologic methods. Pericardial swabs were used to inoculate horse blood agar (Oxoid, Unipath Limited, Basingstoke, Hampshire, England) plates and Sabouraud dextrose agar (Unipath) slopes (SAB). All tissue samples were roughly chopped and placed into nutrient broth (Unipath) and thioglycolate broth (Unipath) and incubated at $35^{\circ} \mathrm{C}$ for 48 hours. The broths were then plated onto horse blood agar plates. The subculture from the nutrient broth was incubated aerobically for a further 48 hours at $35^{\circ} \mathrm{C}$. The thioglycollate broth subculture was incubated anaerobically for a further 48 hours at $35^{\circ} \mathrm{C}$. Collection, rinse, and freezing solutions were incubated for 48 hours at $35^{\circ} \mathrm{C}$ followed by subculturing onto horse blood agar plates, which were incubated for a further 48 hours at $35^{\circ} \mathrm{C}$. Rinse solutions and freezing solutions at cryopreservation were inoculated onto $S A B$ slopes. $S A B$ slopes were incubated at $30^{\circ} \mathrm{C}$ for 21 days before they were read. All subculturing of samples and organism identification was done by the microbiology laboratory of the pathology department of TPCH. Valves were not made available for clinical use until all samples taken immediately before cryopreservation were shown to be free of any bacterial or fungal contamination.

For each valve processed for clinical implantation, there were up to 12 specimens ( 6 solutions, 5 tissue pieces, and a pericardial swab) tested for sterility. A summary of the samples used for sterility testing is contained in Table III. Because tissue pieces were the only samples tested for sterility at every stage of valve processing, cryopreservation, and implantation, results of contamination rates for tissue samples form the basis of this review.

Statistical analysis. Data were entered into a spreadsheet program (Exel, Microsoft Corporation, Redmond, Wash.) and $\chi^{2}$ tests were done to determine possible differences in contamination levels between comparable tissue groups. A $p$ value $<0.05$ was considered statistically significant.

\section{Results}

Results for each valve type and subgroup are expressed in Tables IV to VIII. Tables IV and V show microbial contamination rates for multiorgan donor valves with and without antibiotic incubation, respectively. Table VI shows contamination in the heart transplant recipient donor group. Tables VII and VIII indicate contamination for postmortem valves collected with and without antibiotic collection solution, respectively. Table IX is a compilation of the results for all valves separated into those incubated in antibiotics and those not incubated. The discard rate as a result of microbiologic con- 
Table III. Samples for sterility assessment obtained at valve collection, trimming, cryopreservation, and implantation for valves collected from donor and postmortem groups

\begin{tabular}{|c|c|c|c|c|}
\hline \multirow[b]{2}{*}{ Sample } & \multicolumn{2}{|c|}{ Donor } & \multicolumn{2}{|c|}{ Postmortem } \\
\hline & $\begin{array}{c}\text { With } \\
\text { incubation }\end{array}$ & $\begin{array}{c}\text { No } \\
\text { incubation }\end{array}$ & $\begin{array}{c}\text { Collection } \\
\text { solution }\end{array}$ & $\begin{array}{c}\text { No collection } \\
\text { solution }\end{array}$ \\
\hline \multicolumn{5}{|l|}{ At collection } \\
\hline Pericardial swab & - & - & Yes & Yes \\
\hline Tissue & - & - & Yes & - \\
\hline Collection solution & - & - & Yes & - \\
\hline \multicolumn{5}{|l|}{ At valve trimming } \\
\hline Tissue & Yes & Yes & Yes & Yes \\
\hline Rinse solution & Yes & Yes & Yes & Yes \\
\hline \multicolumn{5}{|l|}{ At cryopreservation } \\
\hline Postincubation aortic tissue & Yes & - & Yes & Yes \\
\hline Incubation solution aortic & Yes & - & Yes & Yes \\
\hline Postincubation pulmonary tissue & Yes & - & Yes & Yes \\
\hline Incubation solution pulmonary & Yes & - & Yes & Yes \\
\hline Freezing solution & Yes & Yes & Yes & Yes \\
\hline \multicolumn{5}{|l|}{ At implantation } \\
\hline Tissue & Yes & Yes & Yes & Yes \\
\hline Freezing solution & Yes & Yes & Yes & Yes \\
\hline
\end{tabular}

Table IV. Contamination rates and commonly isolated organisms in tissue samples obtained from multiorgan donor valves incubated for 6 hours at $37^{\circ} \mathrm{C}$ in $M 199+A B$

\begin{tabular}{|c|c|c|c|c|c|c|}
\hline \multicolumn{2}{|l|}{ Tissue sample } & \multicolumn{3}{|c|}{ Samples contaminated } & \multicolumn{2}{|l|}{ Common isolates } \\
\hline Source & $n$ & $n$ & $\%$ & $C I$ & Organism & $n$ \\
\hline \multirow[t]{5}{*}{ Trimming } & 53 & 5 & 9 & $3-21$ & Staphylococcus epidermidis & 2 \\
\hline & & & & & Candida albicans & 1 \\
\hline & & & & & Coliforms & 1 \\
\hline & & & & & S. aureus & 1 \\
\hline & & & & & Acinetobacter sp. & 1 \\
\hline Aortic postincubation & 53 & 1 & 2 & $0-11$ & Candida albicans & 1 \\
\hline Pulmonary postincubation & 53 & 1 & 2 & $0-11$ & Candida albicans & 1 \\
\hline Aortic at implant & 32 & 1 & 3 & $0-16$ & S. epidermidis & 1 \\
\hline Pulmonary at implant & 29 & 0 & 0 & $0-12$ & - & \\
\hline Total at implant & 61 & 1 & 2 & $0-10$ & S. epidermidis & 1 \\
\hline
\end{tabular}

CI, $95 \%$ confidence interval.

tamination was low. Of the 642 collections $31(5 \%)$ showed contamination by bacteria or fungi in tissue or solution samples at the time of cryopreservation and the valves from these collections were discarded. In the immediate postoperative period $(<30$ days) endocarditis developed in only two patients. In both cases the causative organism was not present in any samples during valve processing. The actuarial freedom from endocarditis at 15 years in the current group of patients who received cryopreserved valves is $94 \% \pm 2 \%$.

\section{Discussion}

The high contamination rate of multiorgan donor valves at trimming, $9 \%$ to $14 \%$ (Tables IV and V), is similar to that in published data. ${ }^{5,16}$ At trimming donor valves showed the presence of skin, respiratory, and gastrointestinal tract flora. The gastrointestinal tract organisms, Candida albicans and coliforms, indicated possible contamination during retrieval. This could occur if the bowel was perforated during the removal of mesenteric lymph nodes for tissue typing purposes and the heart was subsequently removed with the same instruments.

The heart transplant recipient valve group was the only donor group with a low contamination rate $(2 \%)$ at trimming (Table VI). This group differs from multiorgan donors in two important areas. First, all hearts were excised by TPCH cardiac surgeons with a very short time exposure to the 
Table V. Contamination rates and commonly isolated organisms in tissue samples obtained from multiorgan donor valves not incubated in $M 199+A B$

\begin{tabular}{|c|c|c|c|c|c|c|}
\hline \multicolumn{2}{|l|}{ Tissue sample } & \multicolumn{3}{|c|}{ Samples contaminated } & \multicolumn{2}{|l|}{ Common isolates } \\
\hline Source & $n$ & $n$ & $\%$ & $C I$ & Organism & $n$ \\
\hline \multirow[t]{4}{*}{ Trimming } & 71 & 10 & 14 & $7-24$ & Staphylococcus epidermidis & 3 \\
\hline & & & & & S. aureus & 2 \\
\hline & & & & & Coliforms & 2 \\
\hline & & & & & Viridans streptococcus & 2 \\
\hline \multirow[t]{2}{*}{ Aortic at implant } & 56 & 13 & 23 & $13-36$ & S. epidermidis & 7 \\
\hline & & & & & Diphtheroid sp. & 2 \\
\hline \multirow[t]{2}{*}{ Pulmonary at implant } & 43 & 8 & 19 & $9-34$ & S. epidermidis & 4 \\
\hline & & & & & Diphtheroid sp. & 2 \\
\hline \multirow[t]{2}{*}{ Total at implant } & 99 & 21 & 21 & $13-30$ & S. epidermidis & 11 \\
\hline & & & & & Diphtheroid sp. & 4 \\
\hline
\end{tabular}

CI, $95 \%$ confidence interval.

Table VI. Contamination rates and commonly isolated organisms in tissue samples obtained from heart transplant recipient valves not incubated in $M 199+A B$

\begin{tabular}{|c|c|c|c|c|c|c|}
\hline \multicolumn{2}{|l|}{ Tissue sample } & \multicolumn{3}{|c|}{ Samples contaminated } & \multicolumn{2}{|c|}{ Common isolates } \\
\hline Source & $n$ & $n$ & $\%$ & $C I$ & Organism & $n$ \\
\hline Trimming & 47 & 1 & 2 & $0-12$ & Staphylococcus aureus & 1 \\
\hline Aortic at implant & 38 & 0 & 0 & $0-10$ & - & - \\
\hline Pulmonary at implant & 1 & 0 & 0 & - & - & - \\
\hline
\end{tabular}

Table VII. Contamination rates and commonly isolated organisms in tissue samples obtained from postmortem valves collected into $M 199+A B$

\begin{tabular}{|c|c|c|c|c|c|c|}
\hline \multicolumn{2}{|l|}{ Tissue sample } & \multicolumn{3}{|c|}{ Samples contaminated } & \multicolumn{2}{|l|}{ Common isolates } \\
\hline Source & $n$ & $n$ & $\%$ & $C I$ & Organism & $n$ \\
\hline \multirow[t]{7}{*}{ Collection } & 339 & 184 & 54 & $48-60$ & Staphylococcus epidermidis & 70 \\
\hline & & & & & Viridans streptococcus & 58 \\
\hline & & & & & Nonhemolytic streptococcus & 28 \\
\hline & & & & & Coliforms & 17 \\
\hline & & & & & Group B $\beta$-hemolytic streptococcus & 16 \\
\hline & & & & & S. aureus & 15 \\
\hline & & & & & Bacillus sp. & 11 \\
\hline \multirow[t]{4}{*}{ Trimming } & 345 & 38 & 11 & $8-15$ & Viridans streptococcus & 9 \\
\hline & & & & & Coliforms & 10 \\
\hline & & & & & S. epidermidis & 5 \\
\hline & & & & & Pseudomonas sp. & 4 \\
\hline Aortic postincubation & 345 & 13 & 4 & $2-7$ & Coliforms & 7 \\
\hline \multirow[t]{2}{*}{ Pulmonary postincubation } & 342 & 11 & 3 & $1-5$ & Coliforms & 4 \\
\hline & & & & & Pseudomonas sp. & 2 \\
\hline Aortic at implant & 244 & 3 & 1 & $0-3$ & S. epidermidis & 3 \\
\hline Pulmonary at implant & 101 & 6 & 6 & $2-13$ & S. epidermidis & 2 \\
\hline Total at implant & 345 & 9 & 3 & $1-5$ & S. epidermidis & 5 \\
\hline
\end{tabular}

CI, 95\% confidence interval.

theater environment and, second, the thoracic cavity was completely isolated from the abdominal cavity.

Postmortem valves retrieved in open mortuary areas show a very high rate of microbial contamination at collection (54\%) (Table VII). The most common isolates were skin and respiratory flora, which indicated contamination from the mortuary atmosphere during collection. This is to be expected inasmuch as tissue may be exposed to atmospheric fallout for up to 10 minutes during collection. This 
Table VIII. Contamination rates and commonly isolated organisms in tissue samples obtained from postmortem valves not collected into $M 199+A B$

\begin{tabular}{|c|c|c|c|c|c|c|}
\hline \multicolumn{2}{|l|}{ Tissue sample } & \multicolumn{3}{|c|}{ Samples contaminated } & \multicolumn{2}{|l|}{ Common isolates } \\
\hline Source & $n$ & $n$ & $\%$ & $C I$ & Organism & $n$ \\
\hline \multirow[t]{4}{*}{ Trimming } & 126 & 13 & 10 & $5-17$ & Viridans streptococcus & 3 \\
\hline & & & & & Coliforms & 3 \\
\hline & & & & & Gram-negative bacillus & 2 \\
\hline & & & & & Staphylococcus aureus & 2 \\
\hline \multirow[t]{3}{*}{ Aortic postincubation } & 126 & 6 & 5 & $2-11$ & Gram-negative bacillus & 2 \\
\hline & & & & & Candida albicans & 1 \\
\hline & & & & & Coliforms & 1 \\
\hline \multirow[t]{2}{*}{ Pulmonary postincubation } & 125 & 2 & 2 & $1-7$ & Gram-negative bacillus & 1 \\
\hline & & & & & S. aureus & 1 \\
\hline Aortic at implant & 91 & 4 & 4 & $1-10$ & S. epidermidis & 2 \\
\hline Pulmonary at implant & 45 & 4 & 9 & $2-22$ & S. epidermidis & 2 \\
\hline Total at implant & 136 & 8 & 6 & $2-12$ & S. epidermidis & 4 \\
\hline
\end{tabular}

CI, 95\% confidence interval.

Table IX. Contamination rates for tissue samples obtained from all valves that were incubated in $M 199+A B$ and those not incubated in $M 199+A B$

\begin{tabular}{|c|c|c|c|c|c|c|c|c|}
\hline \multirow[b]{3}{*}{ Tissue source } & \multicolumn{4}{|c|}{ Incubated } & \multicolumn{4}{|c|}{ Not incubated } \\
\hline & \multirow[b]{2}{*}{ Samples $(n)$} & \multicolumn{3}{|c|}{ Contamination } & \multirow[b]{2}{*}{ Samples $(n)$} & \multicolumn{3}{|c|}{ Contamination } \\
\hline & & $n$ & $\%$ & $C I$ & & $n$ & $\%$ & $C I$ \\
\hline Collection & 339 & 184 & 54 & $48-60$ & - & - & - & - \\
\hline Trimming & 524 & 55 & 11 & $8-14$ & 118 & 11 & 9 & $4-16$ \\
\hline Aortic postincubation & 524 & 20 & 4 & $2-6$ & - & - & - & - \\
\hline Pulmonary postincubation & 520 & 14 & 3 & $1-5$ & - & - & - & - \\
\hline Aortic at implant & 367 & 8 & 2 & $1-4$ & 94 & 13 & 14 & $7-23$ \\
\hline Pulmonary at implant & 175 & 10 & 6 & $2-11$ & 44 & 8 & 18 & $7-31$ \\
\hline Total implant & 542 & 18 & 3 & $1-5$ & 138 & 21 & 15 & $10-23$ \\
\hline
\end{tabular}

CI, $95 \%$ confidence interval.

high level of contamination is significantly reduced to $11 \%(p<0.05)$ by the time the valve is trimmed. This indicates the effectiveness of a short exposure to an antibiotic solution during transportation from the collection site to the processing site and during valve trimming. In addition, being atmospheric, the majority of contamination is washed from the surface of the heart-valve block during transport in nutrient medium with antibiotics.

Samples taken at trimming of postmortem valves with no collection solution (Table VII) demonstrated a level of contamination (10\%) similar to that of postmortem valves with collection solution (11\%) at the time of trimming. This is probably in part the result of the retrieval of these valves from clean room environments. This low rate of contamination was also similar to that of donor valves at trimming ( $9 \%$ to $14 \%$ ) (Tables IV and V).

A $37^{\circ} \mathrm{C}$, 6-hour incubation in M199+AB significantly reduced contamination from $11 \%$ to $3 \%$ or
$4 \%(p<0.05)($ Table IX). This indicated that the type of antibiotics, the low concentrations of the antibiotics, the incubation temperature, and the incubation period are sufficient to sterilize the vast majority of heart valves processed.

Because only those valves that had no demonstrable contamination in tissues or solutions at the time of cryopreservation were implanted, it can be inferred that any contamination at the time of implant arose from the operative field. Furthermore, tissue samples at implant showed contamination by common skin flora, such as Staphylococcus epidermidis, Micrococcus sp., and diphtheroids, which also suggests contamination from the operative field. As seen from Table IX, at implant, valves that were not incubated in $\mathrm{M} 199+\mathrm{AB}$ showed a much higher rate of contamination $(15 \%)$ compared with the rate in valves that had been incubated $(3 \%)(p<0.05)$. The valves that were incubated with antibiotics appeared to have a residual antibiotic effect that destroyed 
contaminating bacteria or inhibited their growth. The presence of antibiotics in the implanted tissue may play a contributory role in the early postoperative period during which allografts demonstrate a low rate of bacterial endocarditis ${ }^{8}$ compared with other valve prostheses. During the whole experience at TPCH only two patients who received allograft valves had endocarditis after operation in the first 3 months. In both cases the causative organism was never present in any of the many samples tested for sterility during valve processing. In the presence of active endocarditis, no implanted allograft valve was affected by endocarditis. ${ }^{18}$

Amphotericin B has been removed from some valve incubation protocols ${ }^{10,16}$ because of its effect on viability. Fungal contamination of valves in this review was low $(<2 \%)$ and often associated with contamination by other gastrointestinal tract organisms such as coliforms. The presence of gastrointestinal tract organisms in postmortem valves is likely a result of microbial migration through the blood stream and diaphragm in the postmortem interval. With maintenance of a strict protocol of retrieval within 24 hours of death (mean 15 hours) such contamination was minimized. Valves showing contamination with fungal organisms at cryopreservation were discarded. This protocol of early retrieval has been in effect for 25 years since the commencement of the allograft heart valve program at TPCH. The aspect of clean removal as soon as possible after death is considered most important. Donor valves with contaminating gastrointestinal tract flora were probably procured after all other organs and lymph nodes had been removed or possibly when isolation between the thoracic and abdominal operative fields had not been maintained. Improvements in technique have minimized these risks.

The postmortem retrieval of valves from cadavers can produce valves with microbial contamination levels as low as those obtained from multiorgan donors in a sterile theater environment by the time of the trimming step of processing. Shortterm exposure to antibiotics during transportation or trimming may wash off surface contaminants from atmospheric fallout during retrieval. Incubation of valve tissue in penicillin, $30 \mu \mathrm{g} / \mathrm{ml}$, and streptomycin, $50 \mu \mathrm{g} / \mathrm{ml}$, at $37^{\circ} \mathrm{C}$ for 6 hours is a sufficient antibiotic treatment to decontaminate the vast majority of valves and has the benefits of being low cost, nontoxic, and convenient. Procurement of valves within 24 hours of death at postmortem examination produces valves with low levels of contamination by gastrointestinal tract organisms.

The TPCH protocol for allograft heart valve antibiotic sterilization is unlikely to be effective if collection from postmortem sources is prolonged beyond 24 hours of death, if there is any delay in transport before the valves are processed, and in particular if antibiotics are not used immediately at postmortem collection. It is recognized that the penicillin and streptomycin regimen is different from the modern-day broad-spectrum multiple antibiotic regimen used by most centers and tissue banks. At TPCH, this protocol has stood the test of time (25 years), has proved effective, and demands no change.

\section{Recommendations}

1. Retrieve valve as soon as possible after death.

2. Retrieve valve in as sterile a manner as possible.

3. Expose all valves to antibiotics. For heart-only donor and transplant recipient valves, minimal exposure during trimming of the valves is sufficient. All other valves should be considered contaminated and be incubated in nutrient medium with antibiotics for 6 hours at $37^{\circ} \mathrm{C}$.

4. If there is any doubt about the sterility, the protocol is (1) thaw and culture the pulmonary valve, (2) perform a Gram stain procedure on the freezing solution while the DMSO is being washed from the valve just before implant, or (3) discard.

5. Discard all valves that demonstrate fungal contamination at trimming.

6. Specimens of tissue trimmed from grafts at the time of implant must be sent for culture. It is important clinically to know the valve is sterile to correlate this with the subsequent progress of the patient's condition.

7. Procurement personnel should remove the heart from multiorgan donors with new gloves and clean instruments, and if possible the thoracic and abdominal operative fields should be isolated to reduce the risk of contamination from the gastrointestinal system.

8. Any surgical department intending to adopt this TPCH protocol of low-dose, short-exposure antibiotic sterilization must ensure collection is done within 24 hours of death and ascertain its own initial and follow-up contamination rates.

We thank the laboratory staff of the Department of Microbiology at TPCH for their invaluable assistance with specimen testing and organism identification. Ian Smith, 
MApSc (Med Phys), is also thanked for his assistance with the analysis of the data.

\section{REFERENCES}

1. Longmore DB, Lockey E, Ross DN, Pickering BN. The preparation of aortic valve homografts. Lancet 1966;2:463-4.

2. Beech PM, Bowman FO Jr, Kaiser GA, Malm JR. Frozen irradiated aortic valve homografts. N Y State J Med 1973;19:651-4.

3. Smith JC. The pathology of human aortic valve homografts. Thorax 1967;22:114-38.

4. Manhas DR, Mohri H, Merendino KA. Late results of beta-propiolactone sterilized aortic homograft valves. Am J Surg 1973;126:255-62.

5. Yacoub M, Kittle CF. Sterilization of valve homografts by antibiotic solutions. Circulation 1970; 41(Suppl):II29-31.

6. Bolooki H, Rubinson RM, Prochazka J, Jude JR. A simple method of aortic homograft valve sterilization and preservation. J Thorac CARdiovasc Surg 1972; 63:249-57.

7. Watts LK, Duffy MB, Field RB, et al. Establishment of a viable homograft valve bank: a rapid method of determining homograft viability. Ann Thorac Surg 1976;21:230-6.

8. O'Brien MF, Stafford EG, Gardner MAH, Pohlner PG, McGiffin DC. A comparison of aortic valve replacement with viable cryopreserved and fresh allograft valves with a note on chromosomal studies. J Thorac Cardiovasc Surg 1987;94:812-23.

9. O'Brien MF, Stafford EG, Gardner MAH, et al. Cryopreserved viable allograft aortic valves. In: Yankah AL, Hetzer R, Yacoub MH, Ross DR, Somerville J, Miller C, eds. Cardiac valve allografts
1962-1987. Darmstadt, Germany: Steinkopff Verlag, 1988:311-21.

10. O'Brien MF, McGiffin DC, Stafford EG, et al. Allograft aortic valve replacement: long term comparative clinical analysis of the viable cryopreserved and antibiotic $4^{\circ} \mathrm{C}$ stored valves. J Card Surg 1991; 6(suppl):534-43.

11. O'Brien MF, Stafford EG, Gardner M, et al. The viable cryopreserved allograft aortic valve. J Card Surg 1987;1(suppl):153-67.

12. O'Brien MF, Johnson N, Stafford EG, et al. A study of the cells in the explanted viable cryopreserved allograft valve. J Card Surg 1988;3(suppl):289-96.

13. Van Der Kamp AWM, Nauta J. Fibroblast function and the maintenance of the aortic-valve matrix. Cardiovasc Res 1979;13:167-72.

14. Angell WW, Shumway NE, Koesk JC. A five-year study of viable aortic valve homografts. J THORAC Cardiovasc Surg 1972;64:329-39.

15. Grinath MR, Gavin JB, Strickett MG, Barratt-Boyes BG. The effects of antibiotics and storage on the viability and ultrastructure of fibroblasts in canine heart valves prepared for grafting. Aust N Z J Surg 1974;44:170-2.

16. Lange PL, Hopkins RA. Allograft valve banking: techniques and technology. In: Hopkins RA. Cardiac reconstruction with allograft valves. New York: Springer-Verlag, 1989:37-63.

17. HU J, Gilmer L, Hopkins R, Wolfinbarger L Jr. Effects of antibiotics on cellular viability in porcine heart valve tissue. Cardiovasc Res 1989;23:965-72.

18. McGiffin DC, Galbraith AJ, McLachlan GJ, et al. Aortic valve infection: risk factors for death and recurrent endocarditis after aortic valve replacement. J Thorac CARdiovasc Surg 1992;104:511-9. 